\title{
Performance of pulsed-electrochemical honing and pulsed-electrochemical finishing in improving quality of bevel gears
}

\author{
Sunil Pathak ${ }^{1, *}$ and Neelesh Kumar Jain ${ }^{2}$ \\ ${ }^{1}$ Faculty of Engineering Technology, Universiti Malaysia Pahang, Lebuhraya Tun Razak, 26300 Gambang, Kuantan, Malaysia \\ ${ }^{2}$ Discipline of Mechanical Engineering, Indian Institute of Technology Indore, MP, India
}

Received: 7 August 2018 / Accepted: 7 September 2018

\begin{abstract}
This article presents a comparative study concerning performance of pulsed-electrochemical honing $(\mathrm{PECH})$ and pulsed-electrochemical finishing (PECF) in straight bevel gear finishing. Performance of these processes were compared in terms of average percentage difference in the considered parameters of surface features of bevel gear namely average percentage differences in average surface roughness 'PD $R_{\mathrm{a}}$ ', maximum surface roughness ' $\mathrm{PD} R_{\max }$ ' and depth of surface roughness ' $\mathrm{PD} R_{\mathrm{z}}$ ', micro-geometry (i.e. average percentage differences in single pitch error ' $\mathrm{PD} f_{\mathrm{p}}$ ', adjacent pitch error ' $\mathrm{PD} f_{\mathrm{u}}$ ', cumulative pitch error ' $\mathrm{PD} F_{\mathrm{p}}$ ', and percentage difference in runout ' $\mathrm{PD} F_{\mathrm{r}}$ ') and finishing productivity (i.e. material removal rate 'MRR'). Microstructure and microhardness were also considered as measure for performance assessment. Observed results show $\mathrm{PECH}$ is proficient in simultaneously improving all the considered responses of bevel gears by more than $50 \%$ as compared to PECF. The PECH-finished gear additionally displayed unrivalled microstructure and better microhardness when contrasted with PECF-finished gear. These changes will upgrade the working-life and operating performance of the finished gear.
\end{abstract}

Keywords: Gears / surface finish / micro-geometry / honing / PECH / PECF

\section{Introduction}

Gears have been developed as one of the most economical element to transfer power and motion between the two shafts with/without affecting the speed and direction. Gear has been employed at various operations due to their unique capabilities, some of the noteworthy applications are automotive, aerospace, marine, other modes of transportation, machine tools, control systems, cement plants, rubber industries, iron ore extraction, steel plants, toys, office equipment, home appliance, etc. [1]. Surface quality of gears is considered as one of the most important criteria while their selection during use. It can be evaluated in various defined measures such as surface finish, micro-geometry, hardness, toughness, fatigue strength, microstructure, etc.

Conventional gear manufacturing processes (such as hobbing, milling, revacycle, etc.) do not yield acceptable surface attributes thus failing to meet the requirements of the end users. For example, gears manufactured by hobbing and shaping have tool marks and scallops on the gear tooth surface. Post-manufacturing heat treatment to improve gear hardness also adversely affects the surface characteristics of the gears. Therefore, need of an accurate

\footnotetext{
* e-mail: sunilpathak@ump.edu.my
}

gear finishing process becomes necessary to ensure better surface attributes of a gear to eliminate various defects and sub-surface damages induced during the gear manufacturing and heat treatment processes. This problem of finding accurate finishing process becomes more vital in case of bevel gear finishing due to its complicated tooth geometry, which possesses octoid form with profile as well as top land changing from back to apex, this makes finishing of it becomes much difficult as compared to finishing of cylindrical gears. Because of its complicated geometry mainly two gear finishing processes, namely gear grinding and gear lapping, have been commonly used to improve its surface attributes. These two processes also have their certain limitation such as Gear grinding may lead to provide thermal damages (i.e. grind burns) on the tooth profile, which may affects the surface integrity of gears, while Gear lapping adversely affects the profile of gears if performed for longer duration. Also they suffered from early tool breakage, higher repair cost and longer finishing time which make them less productive [2]. All such diminishing assets of conventional finishing processes increase the need of development of non-conventional finishing operations which can fill the gap and help in producing gears of demanded quality without costing more as compared to conventional processes. This requires an 
investigation on advanced gear finishing processes, for example, pulsed-electrochemical honing (PECH) process. $\mathrm{PECH}$ is a precision finishing process combining activities and benefits of pulsed-electrochemical finishing (PECF) and traditional honing in a singular process and incapacitating their weaknesses at the same time. PECH standout among the prospective hybrid finishing processes consolidating the rapid material-removal capacity of PECF and capacity of refining geometry-related inaccuracies of the traditional honing. Likewise, utilization of pulsed current in $\mathrm{ECH}(\mathrm{PECH})$ gives the ease time to the process during the pulse-off time to discharge the sludge products out of the IEG and accordingly keeping up a clean IEG to enhance the process capacity [3].

Very limited references are available on finishing of gears especially bevel gears by ECH and a very few on finishing gears by PECH. Practice of ECH for refining the surface finish of the hardened helical gear was first considered by Capello and Bertoglio [4]. There innovation consists of finishing a helical gear tooth face of involute profile, having module of $2.5 \mathrm{~mm}$ and with 17 number of teeth, mating with an individually designed cathode tool of helical gear having 64 teeth. Chen et al. [5], Wei et al. [6], He et al. [7] and Yi et al. [8] have used ECH for spur gear finishing and noticed better surface roughness and accuracy of tooth profile as compared to the unfinished gears. Their work emphasizes on stabilizing ECH as one of the potential process to precise micro-geometrical errors and has better productivity than gear grinding. ECH has potential to finish work-piece of any hardness irrespective of their mechanical properties. They also mentioned that there is no any effect of honing tool on the surface attributes of the work-piece gear as honing tool only used to scrap the protective metal-oxide film generated over the anodic work-piece gear during their anodic dissolution. Mishra et al. [9] finish helical gears made of EN8 by ECH and explored the influence of applied-voltage, electrolyte concentration and work-piece rotary speed on surface roughness using an electrolyte mixture of $25 \% \mathrm{NaNO}_{3}$ and $75 \% \mathrm{NaCl}$. They suggested that electrolyte concentration and applied voltage as noteworthy parameters affecting process capabilities as compared to rotary speed.

Shaikh and Jain [10] finished straight bevel gears by ECH process. They come up with an idea of using complementary cathode gears to encounter the difficulties of synchronized finishing of all teeth of bevel gears by ECH without the need of reciprocating movement to the workpiece gear and ensuring maintenance of required IEG at the same. In the most recent work, Pathak et al. [11-13] further developed PECH for bevel gears and analyze the effects of various process parameters of PECH and their effects on synchronized enhancement of surface quality, microgeometry and surface integrity of the PECH finished gears. They also study the significance of hardened honing gear PECH process [14].

From the available literature it can be suggested that no work has been conveyed on performance assessment of $\mathrm{PECH}$ and PECF for finishing of bevel gear so as to justify the need of honing gear in PECH. Therefore, the present work investigation was done to analyze the performance assessment of PECH with PECF in terms of considered

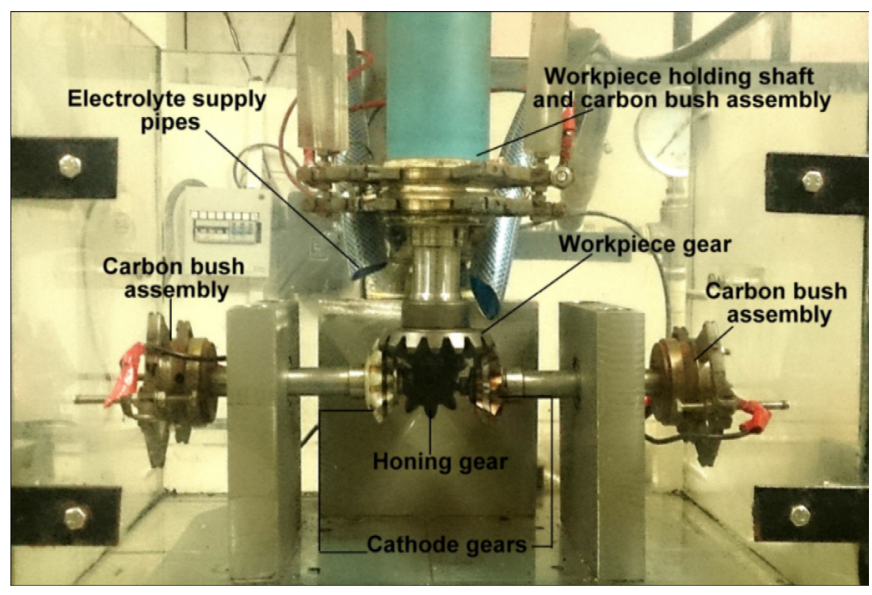

Fig. 1. Finishing chamber photograph depicting arrangement for finishing of straight-bevel gear in PECH.

parameters of surface roughness (in terms of average percentage differences in average surface roughness 'PD $R_{\mathrm{a}}$ ', maximum surface roughness 'PD $R_{\max }$ ' and depth of surface roughness ' $\mathrm{PD} R_{\mathrm{z}}{ }^{\prime}$ ), micro-geometry (in terms of average percentage difference in single pitch error ' $\mathrm{PD} f_{\mathrm{p}}$ ', adjacent pitch error ' $\mathrm{PD} f_{\mathrm{u}}$ ', cumulative pitch error ' $\mathrm{PD} F_{\mathrm{p}}$ ', and percentage difference in runout ' $\mathrm{PD} F_{\mathrm{r}}$ ') and finishing productivity in terms of material removal rate 'MRR' with an objective to justify need of the hybridization of PECF with honing by (i) finishing one workpiece bevel gear by $\mathrm{PECH}$ process; and (ii) finishing the similar workpiece gear by PECF process i.e. using only complementary cathode gears and no honing gear. Both experiments used the optimum values of the $\mathrm{PECH}$ parameters identified from the previous experiments [11,13].

\section{Materials and methods}

The experiments were directed using indigenously developed apparatus of PECH for finishing of the straight bevel gears. Figure 1 shows the photograph of the finishing chamber and details of the setup was presented in Pathak et al. (2014). 20MnCr5 alloy steel was used as material for the specimen gear and honing gear due to their devastating demand in the automotive and space engineering. Various aspects of quality measures for the specimen gear were studied to validate these finding. Experiments was performed using optimized values of input parameters from the pilot and main experiments namely pulse-on time ' $T_{\text {on' }}$ ' $(2 \mathrm{~ms})$, pulse-off time ' $T_{\text {off }}$ ' $(4.5 \mathrm{~ms})$, finishing time ' $t$ ' (6 minutes), electrolyte flow rate ' $F$ ' (20 L per minute) and rotary speed of workpiece gear ' $R$ ' ( $40 \mathrm{rpm})$ (Pathak et al. [13]) and from the main experiments for electrolyte composition ( 75 wt. $\% \mathrm{NaCl}+25$ wt. $\% \mathrm{NaNO}_{3}$ ), electrolyte concentration $(7.5 \mathrm{wt} . \%)$ and applied voltage as 8 volts (Pathak et al. [11,12]).

Surface quality of the PECF and PECH treated bevel gears have been studied in respect of average percentage differences in their surface roughness viz. (i) average surface roughness 'PD $R_{\mathrm{a}}$ '; (ii) maximum surface roughness ' $\mathrm{PD} R_{\text {max }}$ '; and (iii) depth of surface roughness 'PD $R_{\mathrm{z}}$ ', and 
Q2 Table 1. Results for process performance comparison of PECH with PECF in finishing of straight bevel gears.

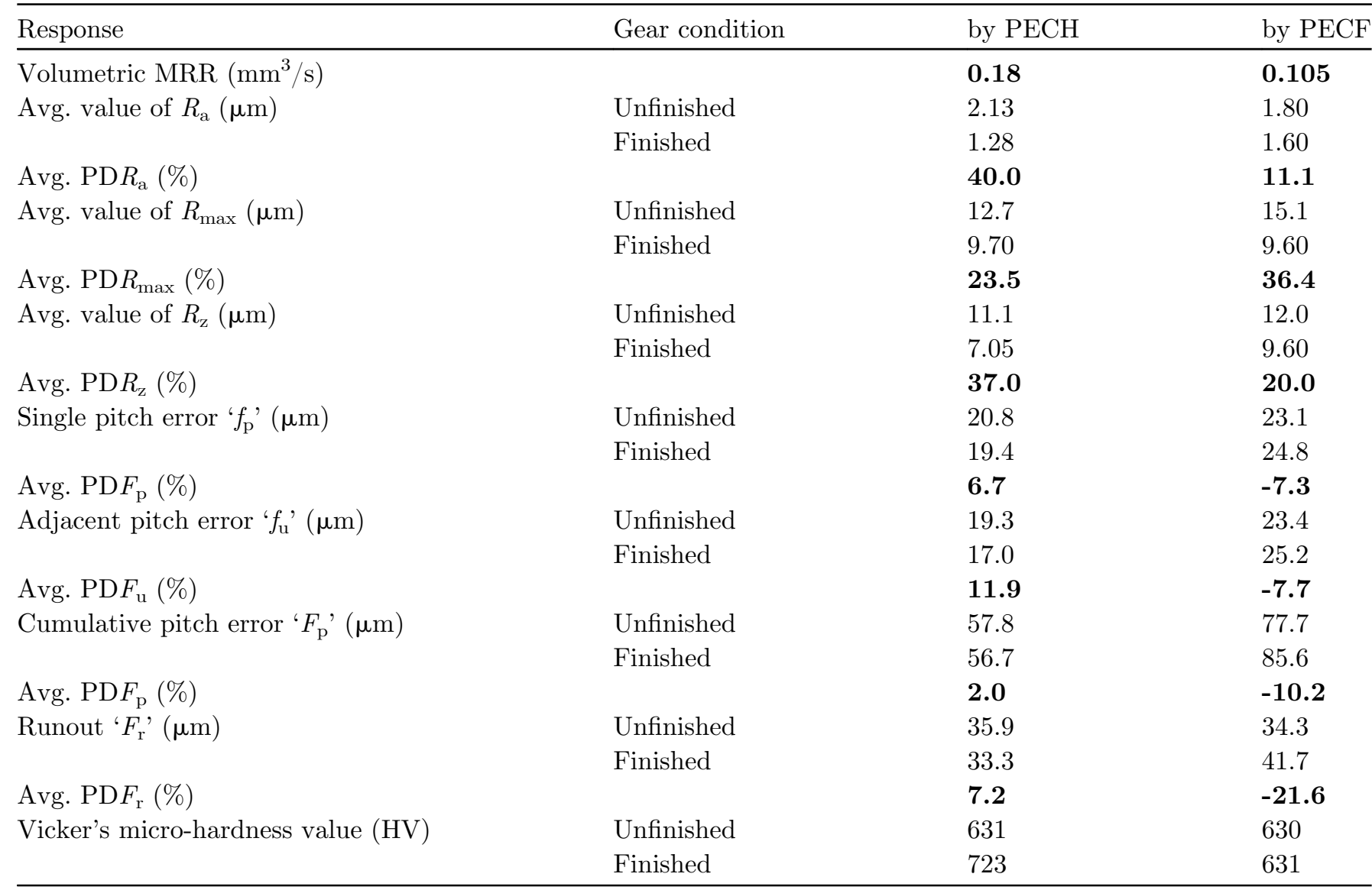

microgeometry is evaluated in terms of average percentage differences in (i) single pitch error ' $\mathrm{PD} f_{\mathrm{p}}$ '; (ii) adjacent pitch error ' $\mathrm{PD} f_{\mathrm{u}}$ '; (iii) cumulative pitch error ' $\mathrm{PD} F_{\mathrm{p}}$ '; and (iv) percentage difference in runout ' $\mathrm{PD} F_{\mathrm{r}}$ '. Finishing productivity has been evaluated in terms of volumetric $\operatorname{MRR}\left(\mathrm{mm}^{3} / \mathrm{sec}\right)$. Surface integrity of the untreated gear, $\mathrm{PECF}$ and PECH-treated gear have been investigated in terms of microstructure and microhardness.

Surface roughness was measured using 3D-surfaceroughness-cum-contour-tracer machine 'LD-130' by Mahr Metrology Germany. Three measurements were taken at different locations along the pitch line on left hand and right hand flanks of two consecutive gear teeth using $0.2 \mathrm{~mm}$ cut-off length and evaluation length of $1.6 \mathrm{~mm}$. Arithmetic average values of the measured values of a roughness parameter of an unfinished gear and the same gear finished by $\mathrm{PECH} / \mathrm{PECF}$ were used to evaluate average percentage difference in that parameter i.e. average percentage difference in average surface roughness value 'PD $R_{\mathrm{a}}$ ' can be calculated using equation (1). Similarly, average percentage difference in maximum surface roughness 'PI $R_{\max }$ ' and average percentage difference in depth of surface roughness 'PI $R_{\mathrm{z}}$ ' were also evaluated using their corresponding measured values.

\section{see equation (1) at the bottom of the page}

Considered parameters of micro-geometry were measured on right hand and left hand flanks of all the 16 teeth of the unfinished and $\mathrm{PECH} / \mathrm{PECF}$ finished bevel gears on the computer numeral controlled (CNC) gear metrology machine Smart-Gear from Wenzel Gear-Tec, Germany. These values were used to compute average values of errors

$$
\begin{aligned}
& \text { Avg. PD } R_{\mathrm{a}} \\
& =\frac{\text { Avg. } R_{\mathrm{a}} \text { value of an untreated gear }- \text { Avg. } R_{\mathrm{a}} \text { value of the same gear treated by } \mathrm{PECH} \text { or PECF }}{\text { Avg. } R_{\mathrm{a}} \text { value of the untreated gear }} \times 100(\%)
\end{aligned}
$$




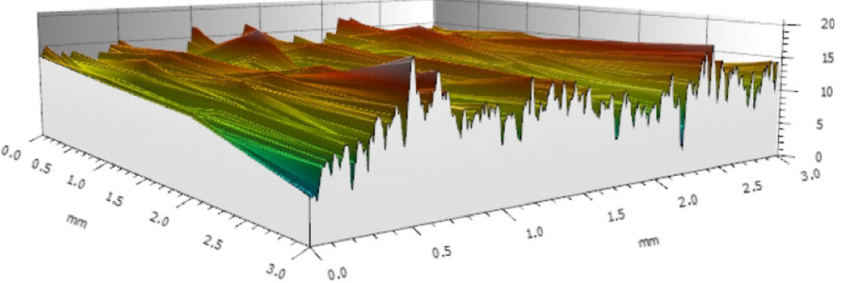

(a)

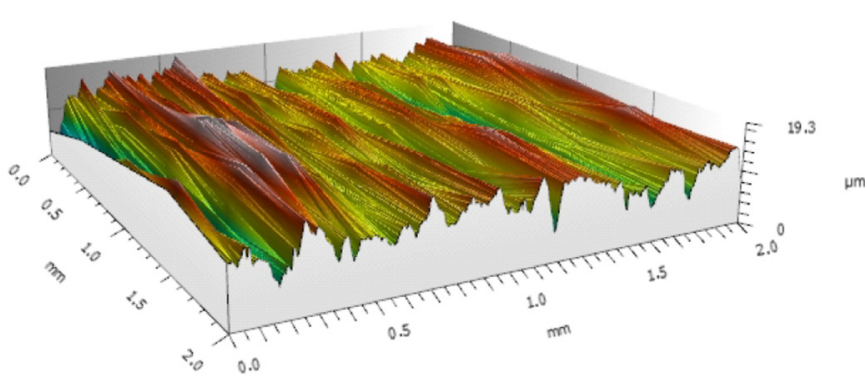

(b)

Fig. 2. 3D surface images of (a) an untreated gear; and (b) PECF treated gear utilizing the identified-optimum combination of process parameters.

in single pitch, adjacent pitch and cumulative pitch i.e. equation (2) was used to compute average value of percentage improvement in single pitch error $\left(\mathrm{PI} f_{\mathrm{p}}\right)$.

\section{see equation (2) at the bottom of the page}

Similarly, average values of percentage difference were computed for error in adjacent pitch $\left(\mathrm{PI} f_{\mathrm{u}}\right)$ and cumulative pitch $\left(\mathrm{PI} F_{\mathrm{p}}\right)$. Concept of runout evaluation yields single value therefore percentage improvement in runout $\left(\mathrm{PI} F_{\mathrm{r}}\right)$ was computed using equation (3). Higher percentage difference in the parameters of roughness (using Eq. (1)) and microgeometry (using Eqs. (2) and (3)) suggests better quality of that particular parameter of surface feature of gear after its treatment by PECH or PECF.

see equation (3) at the bottom of the page

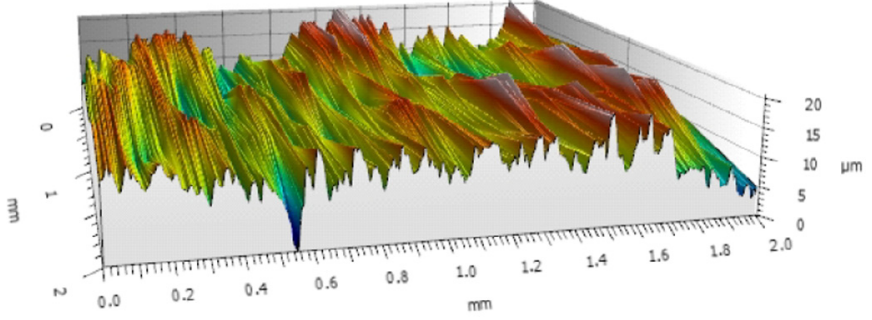

(a)

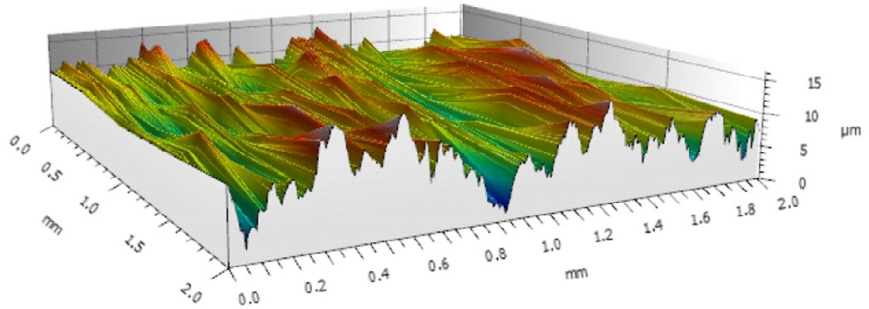

(b)

Fig. 3. 3D surface images of (a) an untreated gear; and (b) $\mathrm{PECH}$ treated gear utilizing the identified-optimum combination of process parameters.

Finishing productivity was evaluated in terms of average value of volumetric MRR which was calculated by dividing the weight loss of the workpiece gear during its finishing by the PECH and PECF process, by the product of the finishing time and density of the workpiece material (Eq. (4)). Weight of the workpiece gear before and after finishing was measured on a precision weighing balance (make Essae-Teraoka Ltd.) having a least count of $10 \mathrm{mg}$.

\section{see equation (4) at the bottom of the page}

Field emission scanning electron microscopy (FESEM), "Supra 55" by Carl Zeiss, was used to analyze the microstructure of the unfinished and PECH/PECF gears. Whereas, hardness testing was done utilizing load and dwell time as $0.5 \mathrm{~kg}$ and 15 seconds respectively using microhardness tester "VMH-002" by Walter UHL, Germany on the gear tooth before finishing and after its finishing by PECH and PECF. Avg. $\mathrm{PD} f_{\mathrm{p}}$
$=\frac{\text { Average } f_{\mathrm{p}} \text { value of an unfinished gear }- \text { Average } f_{\mathrm{p}} \text { value of the same gear finished by PECH or PECF }}{\text { Average } f_{\mathrm{p}} \text { value of the unfinished gear }} \times 100(\%)$

$\mathrm{PD} F_{\mathrm{r}}=\frac{F_{\mathrm{r}} \text { value of an unfinished gear }-F_{\mathrm{r}} \text { value of the same gear finished by PECH or PECF }}{F_{\mathrm{r}} \text { value of the unfinished gear }} \times 100(\%)$

Avg. Vol. MRR $=\frac{\text { weight of an unfinished gear }(\mathrm{g})-\text { weight of the same gear finishined by PECH or PECF }(\mathrm{g})}{\text { Finishing time }(\mathrm{s}) \times \text { Density of the workpiece material }\left(\mathrm{g} / \mathrm{mm}^{3}\right)}\left(\mathrm{mm}^{3} / \mathrm{s}\right)$ 


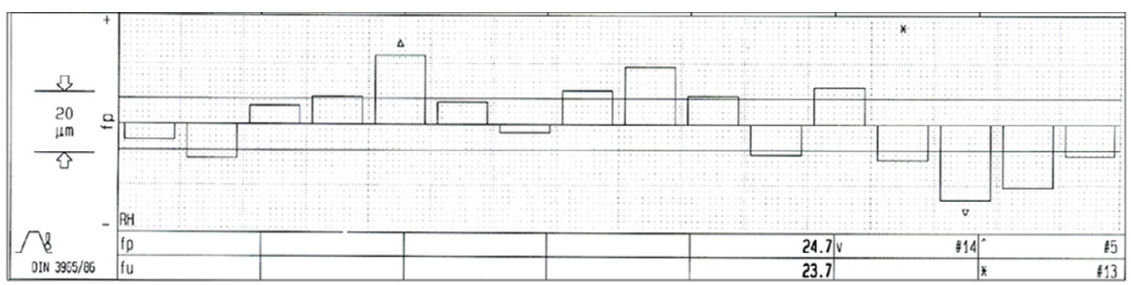

(a)

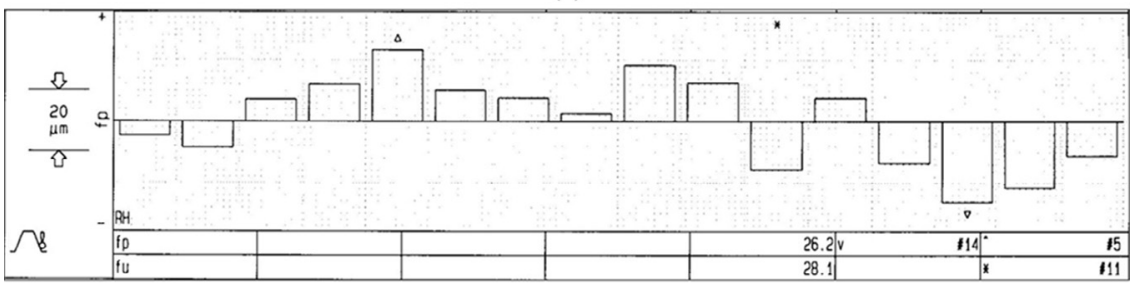

(b)

Fig. 4. Investigations reports generated using CNC gear metrology machine for single pitch deviation and adjacent pitch deviation of bevel gear for (a) an untreated gear; and (b) PECF-treated gear using optimum combination of process parameters.

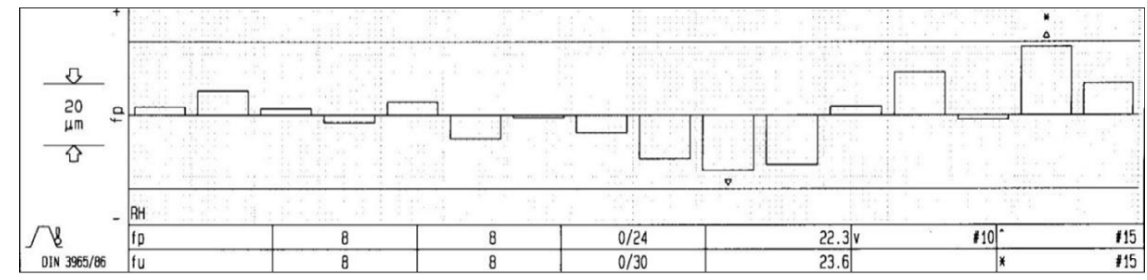

(a)

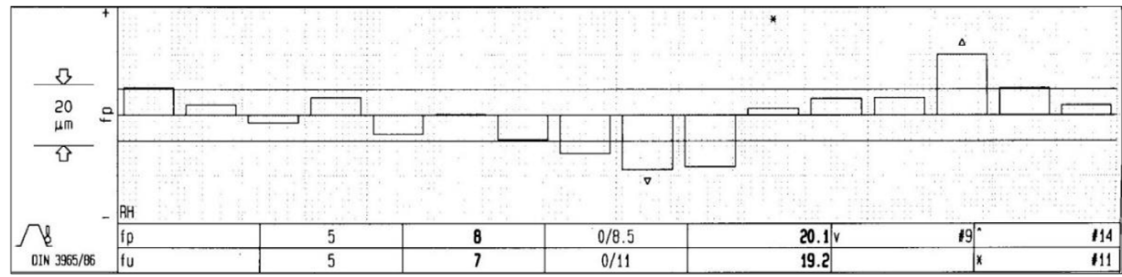

(b)

Fig. 5. Investigations reports generated using CNC gear metrology machine for single pitch deviation and adjacent pitch deviation of bevel gear for (a) an untreated gear; and (b) PECH-treated gear using optimum combination of process parameters.

\section{Results and discussion}

Table 1 presents an assessment of performance of PECH and PECF for bevel gear finishing. Figures 2 and 3 illustrate 3D surface topography of the tooth flank surface for an untreated bevel-gear (Figs. 2a and 3a) and same gear finished by PECF (Fig. 2b) and by PECH (Fig. 3b). Microgeometry profiles have been presented for unfinished gear in Figures 4a, 5a, 6a and 7a, while for gear finished by $\mathrm{PECF}$ in Figures $4 \mathrm{~b}$ and $6 \mathrm{~b}$, while for PECH-treated gear in Figures $5 \mathrm{~b}$ and $7 \mathrm{~b}$. Scanning electron microscopy (SEM) images at $500 \times$ magnification of the tooth flank surface of bevel gear has been presented in Figure 8. Untreated flank surface has been presented in Figure $8 \mathrm{a}$ and c while SEM images of PECF and PECH treated gear have been shown in Figure $8 \mathrm{~b}$ and $\mathrm{d}$, respectively. Following are the noticeable findings that can be annotated from Table 1 and Figures 2-8; (i) PECH gives significantly higher values of volumetric MRR, avg. $\mathrm{PD} R_{\mathrm{a}}$ and avg. $\mathrm{PD} R_{\mathrm{z}}$ while, $\mathrm{PECF}$ gave higher value of avg. $\mathrm{PD} R_{\text {max }}$; (ii) $\mathrm{PECH}$ gives positive values of avg. $\mathrm{PD} f_{\mathrm{p}}$, avg. $\mathrm{PD} f_{\mathrm{u}}$, avg. $\mathrm{PD} F_{\mathrm{p}}$ and $\mathrm{PD} F_{\mathrm{r}}$ while $\mathrm{PECF}$ yields their negative values and resulted in deteriorating the microgeometry of the bevel gear. Increased value of microgeometry errors of PECF finished gear has lower down the Deutsches Institut fur Normung (DIN) quality from DIN 8 to DIN 9 of the bevel gear. Whereas, reduced value of errors in microgeometry of $\mathrm{PECH}$ finished bevel gear has improved the bevel gear quality from DIN 9 to 8; (iii) PECH helps in improving the surface integrity of the workpiece gear by changing its micro-hardness in positive aspects; (iv) PECF removed only few higher peaks leaving the majority of the traced 


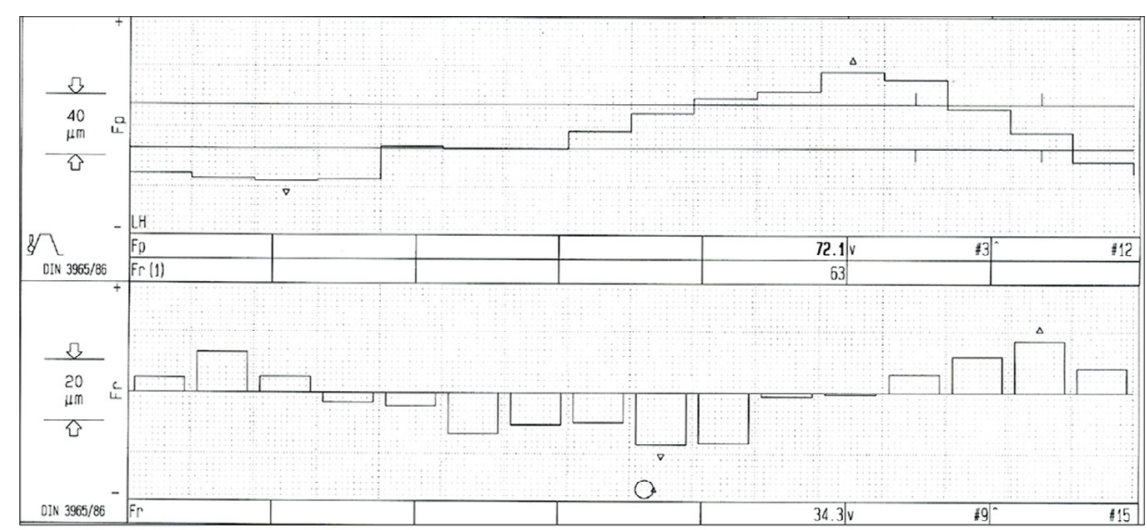

(a)

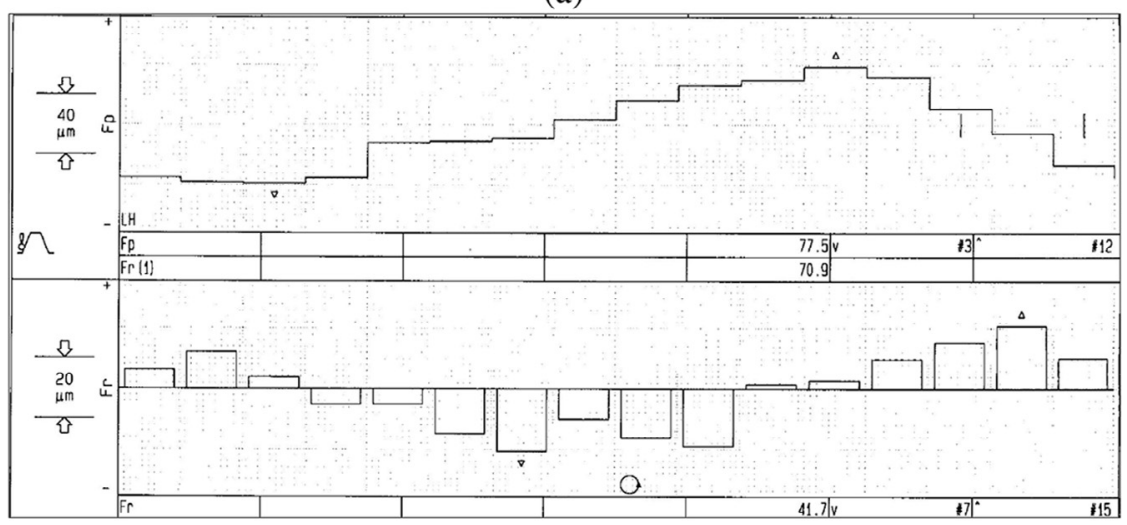

(b)

Fig. 6. Investigations reports generated using CNC gear metrology machine for cumulative pitch error and runout of bevel gear for (a) an untreated gear; and (b) PECF-treated gear using optimum combination of process parameters.

area unfinished. Moreover, it increased unevenness of the flank surface of gears (Fig. 2a and b), whereas majority of the materials removed in PECH treated gear helps in removal of high-peaks which tends to make the tooth surface more uniform and free from irregularities (Fig. 3a and b); and (v) surface abnormalities formed on the toothflank surface of bevel gear during teeth cutting process, surface defects (i.e. pits, cracks, craters, etc.), surface irregularities due to selective electrochemical dissolution and chemical reactions and spots of metal oxide layer are still visible after finishing by PECF (Fig. 8b). Whereas, bevel gear finished by PECH (Fig. 8c) is free from such defects, shows better uniformity and more efficient removal of the metal oxide layer. These results and observations could be explained better using following discussion.

In finishing of the bevel gears by $\mathrm{PECH}$, honing gear plays a vital role as it helps in removing the passivation layer of strong metal oxide layer generated over the tooth flank surface of the workpiece gear during its electrochemical dissolution action. Generation of metal oxide layer on workpiece gear is considered as one of the major limitation of the PECF process, and an efficient removal of it allows more time for PECF to remove material from the workpiece gear tooth flank surface with better uniformity and evenness and eventually helps in improving the microgeometry of the finished gear. Use of hardened honing gear in PECH will also help in removing high peaks from the layer of tooth flank surface, which also allows homogeneity in material removal and thus helps in simultaneous improvement in surface finish and microgeometry of the PECH finished bevel gears. Such uninterrupted and uniform electrolytic dissolution of workpiece material enabling PECH to give higher volumetric MRR $\left(0.18 \mathrm{~mm}^{3} / \mathrm{s}\right)$ as compared to PECF $\left(0.105 \mathrm{~mm}^{3} / \mathrm{s}\right)$. Honing gear also removes surface irregularities by helping in effective removal of peaks from the flank surface of the tooth gear and giving $50 \%$ or more improvement in considered surface features of the bevel gear. Use of hardened gear significantly improves microhardness and microstructure of workpiece gear. All these observations prove that hybrid combination of the two process i.e. PECF and mechanical honing helps in enhancing their process capabilities and overcoming their individual limitations which enable $\mathrm{PECH}$ process to simultaneously improve all the considered surface features of the bevel gears. This ultimately results in improving various performance characteristics of bevel gear during their use.

\subsection{Surface finish}

Figure $2 \mathrm{a}$ and $\mathrm{b}$ depicts the $3 \mathrm{D}$ surface topography of the tooth flank surface of an unfinished bevel gear and same gear finished by PECF and Figure $3 \mathrm{a}$ and $\mathrm{b}$ presents 


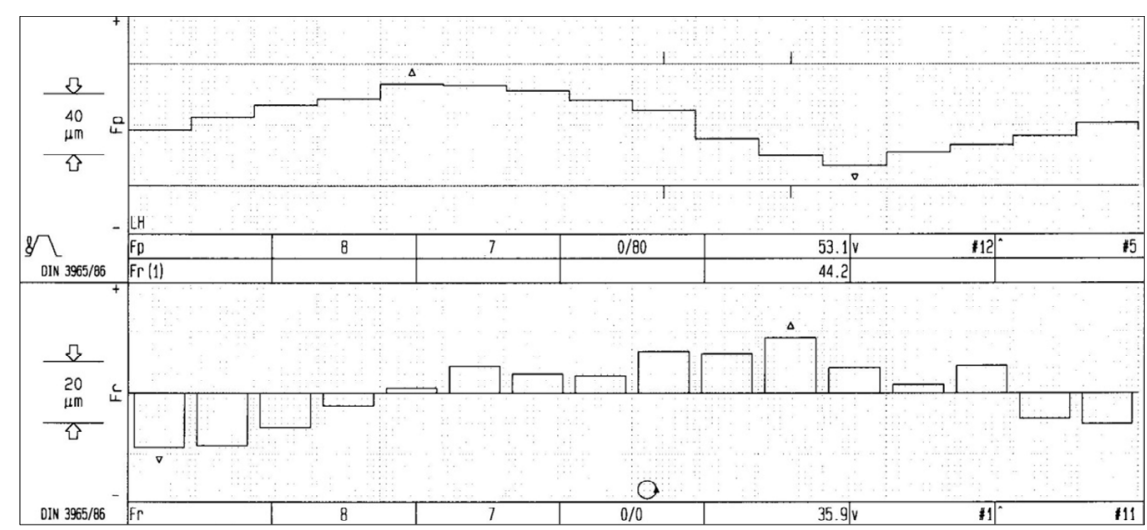

(a)

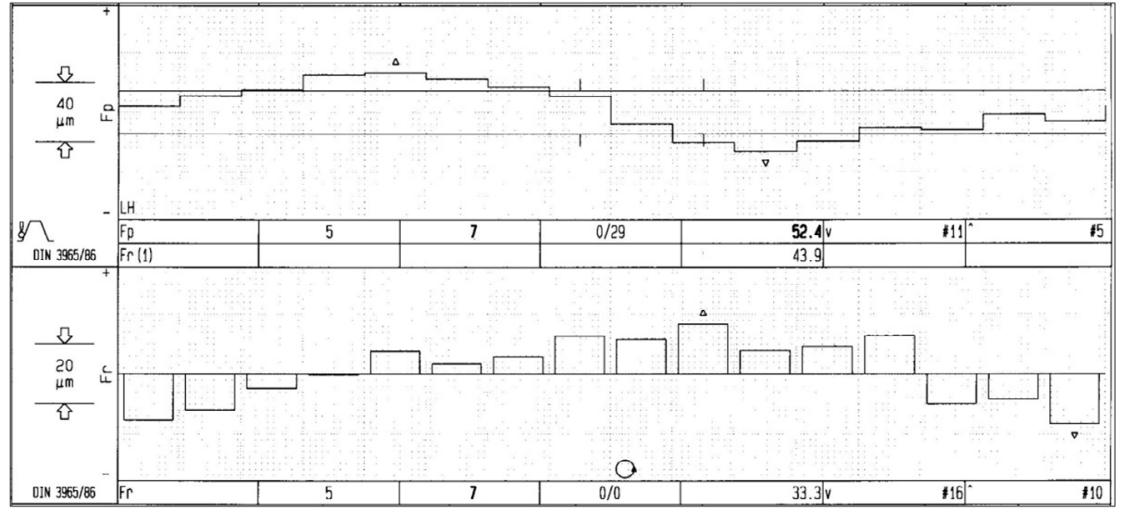

(b)

Fig. 7. Investigations reports generated using CNC gear metrology machine for cumulative pitch error and runout of bevel gear for (a) an untreated gear; and (b) PECH-treated gear using optimum combination of process parameters.

the same for PECH finished utilizing the optimum combinations of input parameters identified from pilot and main experiments. It can be observed on comparing Figure 2a and $\mathrm{b}$ that only few high peaks and spots from the flank surface are removed after finishing by PECF but majority of the scanned section remains unchanged and even show more abrupt surface (Fig. 2b). Whereas, on comparing Figure $3 \mathrm{a}$ and $\mathrm{b}$ it is visible that bulk of the high peaks and spots is smoothened and a uniform surface is achieved after finishing a gear by PECH (Fig. 3b).

\subsection{Micro-geometry}

Results of metrology investigations for an untreated bevel gear (in terms of pitch errors) is presented in Figures 4a and $5 \mathrm{a}$ while Figures $4 \mathrm{~b}$ and $5 \mathrm{~b}$ depict the alike after being treated by PECF and PECH using the optimum combination of PECH-parameters identified from pilot and main experiments. From Figure 4 it can be perceived that the microgeometry features of the bevel gear has diminished after its finishing by PECF as values of single pitch error ' $f$, ' increases $24.7-26.2 \mu \mathrm{m}$ yielding ' $\mathrm{PD} f_{\mathrm{p}}$ ' as $-6.08 \%$ and adjacent pitch error ' $f$ ' ' increases from 23.7 to $28.1 \mu \mathrm{m}$ yielding ' $\mathrm{PD} f_{\mathrm{u}}$ ' as $-18.6 \%$. From Figure 5 , it is visible that the bevel gear quality has been improved after finishing it by PECH as values of single pitch error ' $f_{\mathrm{p}}$ ' reduces from 22.3 to $20.1 \mu \mathrm{m}$ yielding ' $\mathrm{PD} f_{\mathrm{p}}$ ' as $9.8 \%$ and adjacent pitch error ' $f$ ' reduces from 23.6 to $19.2 \mu \mathrm{m}$ yielding ' $\mathrm{PD} f_{\mathrm{u}}$ ' as $18.6 \%$.

Figures $6 \mathrm{a}$ and $7 \mathrm{a}$ present the reports of $\mathrm{CNC}$ gear metrology machine for the unfinished gear in terms of cumulative pitch error and runout, while Figures $6 \mathrm{~b}$ and $7 \mathrm{~b}$ depict the alike after being treated by PECF and PECH using the optimum combination of PECH-parameters. From Figure 6, it is visible that the bevel gear quality has diminished after its finishing by PECF as values of cumulative pitch error ' $F_{\mathrm{p}}$ ' increases $72.1-77.5 \mu \mathrm{m}$ yielding ' $\mathrm{PD} F_{\mathrm{p}}$ ' as $-7.5 \%$ and runout ' $F_{\mathrm{r}}$ ' increases from 34.3 to $41.7 \mu \mathrm{m}$ yielding ' $\mathrm{PD} F_{\mathrm{r}}$ ' as $-24.6 \%$. From Figure 7 it can be observed that the bevel gear quality has been improved after finishing it by PECH as values of cumulative pitch error ' $F_{\mathrm{p}}$ ' reduces from 53.1 to $52.4 \mu \mathrm{m}$ yielding ' $\mathrm{PD} F_{\mathrm{p}}$ ' as $1.32 \%$ and runout ' $F_{\mathrm{r}}$ ' reduces from 35.9 to $33.3 \mu \mathrm{m}$ yielding ' $\mathrm{PD} F_{\mathrm{r}}$ ' as $7.5 \%$. Increased value of errors in microgeometry parameters of PECF finished gear has deteriorated the DIN quality from DIN 8 to DIN 9 of the bevel gear. Whereas, reduced value of errors in microgeometry of PECH finished bevel gear has upgraded the DIN quality from DIN 9 to DIN 8 of bevel gear. It was also found that PECH enhances the microgeometry of bevel gear $50 \%$ more efficiently as compared to PECF. This 


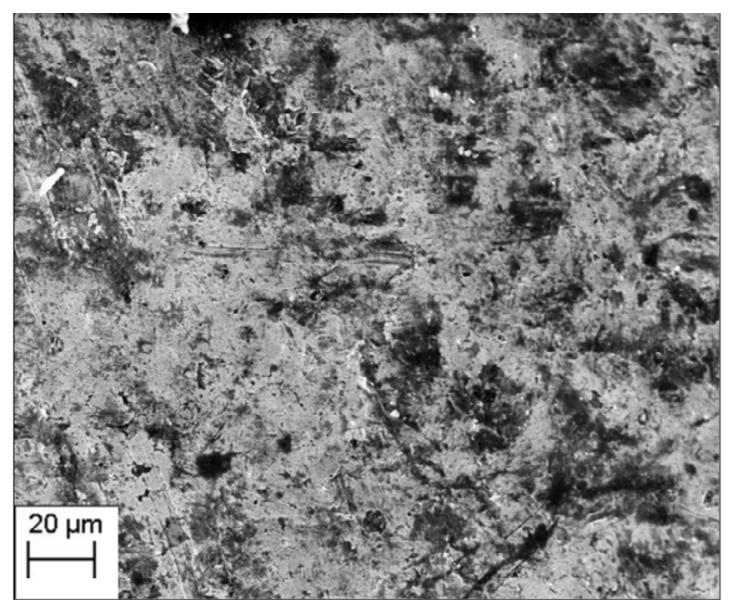

(a)

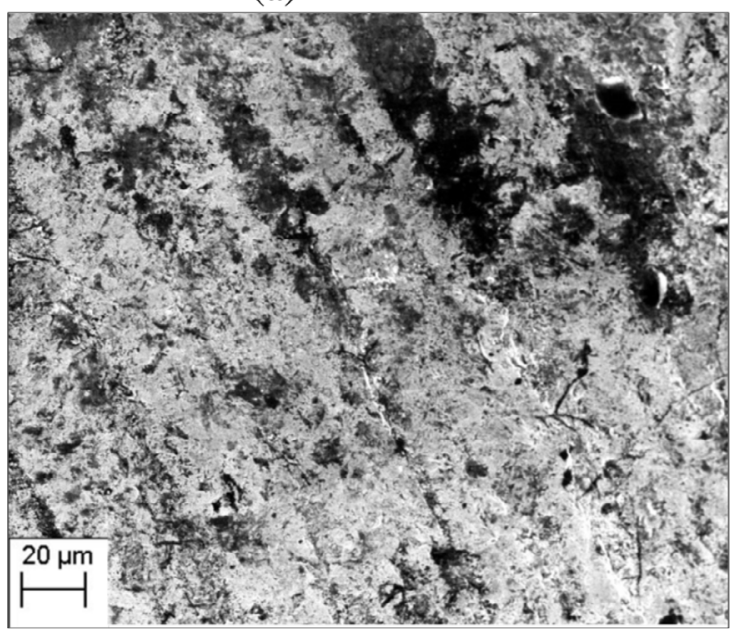

(c)

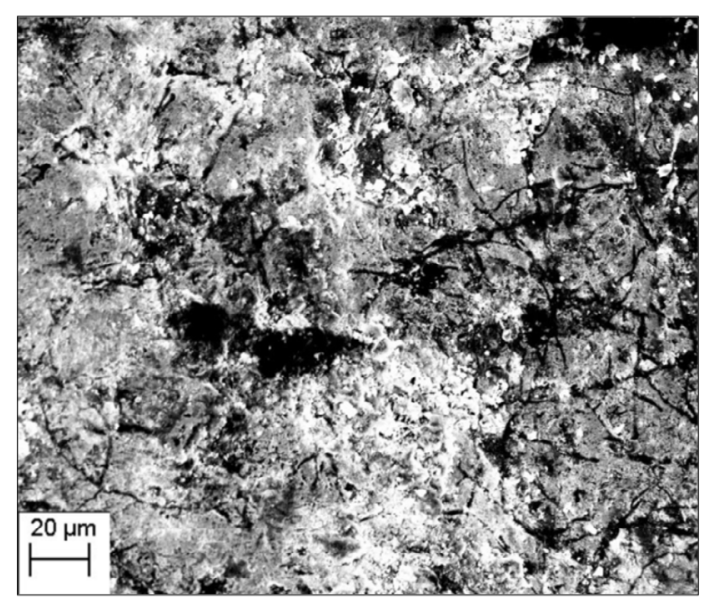

(b)

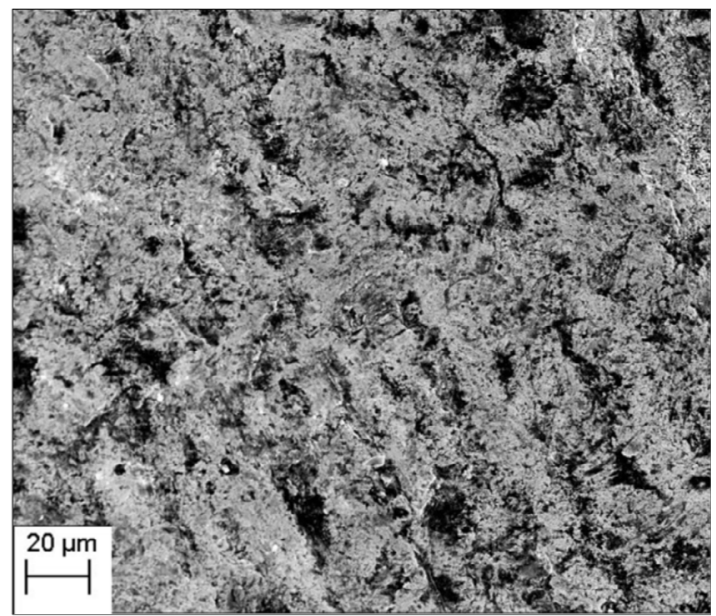

(d)

Fig. 8. Scanning electron microscopy images of the flank surface of a bevel gear tooth at $500 \times$ magnification for (a) an untreated gear; (b) PECF-treated; (c) untreated gear; and (d) PECH-treated.

proves that hybridization of PECF with mechanical honing helps in improving the micro-geometry of a gear and thus helps in reducing the noise generation during their use.

\subsection{Surface morphology and microhardness}

Surface morphology of an untreated bevel gear tooth was studied using SEM at $500 \times$ magnification and presented in Figure 8a and c. It can be perceived from Figure 8a and c that the surface of the gear tooth flank produced during teeth cutting process contains high cutting marks and surface damages (i.e. pits, craters and cracks). Figure 8b and d depicts the SEM images of the tooth flank surface of bevel gear for PECF-treated and PECH-treated, respectively. One can observe from Figure $8 \mathrm{~b}$ that PECF-treated tooth flank surface displays high surface irregularities due to selective electrochemical dissolution, chemical etching and existence of the passivation layer while the PECHtreated tooth flank surface (Fig. 8d) is shows better surface quality and observed free from surface damages. It can also be seen from Figure 8d that the metal oxide layer has been efficiently removed due to presence of hardened honing gear in PECH. Therefore, it can be concluded that the unique combination of PECF and honing i.e. PECH provides superior surface in contrast with PECF.

Investigation was done to test the microhardness change of the tooth flank surface of untreated bevel gear and a gear tooth flank treated by PECF and PECH. It was noticed during these investigations that the value of microhardness remains almost similar (i.e. $630-640 \mathrm{HV}$, Vicker's hardness) for untreated gear and PECF-treated gear. Whereas, the PECH-treated gear tooth flank surface has shown higher values of microhardness (i.e. 713$730 \mathrm{HV}$ ), such variation in the microhardness values are due to the contribution of honing gear which has been hardened using the plasma nitriding process. Since the workpiece gear and honing gear are in tight mesh with almost zero backlash under a particular loading condition, the use of increased hardened honing gear tends to create high dynamic forces during the tightly meshed rotary motion between the workpiece and honing gear. Such involvement of dynamic forces and stresses for continuous period of time may lead to change the surface hardness of the PECH-treated gear in positive manner [14]. 


\section{Conclusions}

Present study evidences that the hybridization of PECF with mechanical honing results in better MRR, improved surface roughness, micro-geometry, microstructure and micro-hardness of bevel gear, as compared to PECF alone. This justifies the need and excellence of process-hybridization of PECF with mechanical honing, i.e., PECH process. This study highlights the role of honing gear in the PECH process and explains its importance in improving surface quality and surface integrity of the PECH-finished bevel gears. The results show that PECH improves quality of the treated gears by more than $50 \%$ in contrast with the PECF process. This study helps in establishing potential of PECH over PECF while it also claims for an advanced apparatus for finishing of various gears for those facing difficulties in finishing by conventional processes. The current study will help to promote PECH to be used in industry.

\section{Nomenclature}

$R_{\mathrm{a}} \quad$ Average surface roughness

$R_{\max } \quad$ Maximum surface roughness

$R_{\mathrm{z}} \quad$ Depth of surface roughness

$f_{\mathrm{p}} \quad$ Single pitch error

$f_{\mathrm{u}} \quad$ Adjacent pitch error

$F_{\mathrm{p}} \quad$ Cumulative pitch error

$F_{\mathrm{r}} \quad$ Runout

DIN Deutsches Institut fur Normung

MRR Material removal rate

HV Vicker's hardness

PECH Pulsed-electrochemical honing

PECF Pulsed-electrochemical finishing

$\mathrm{PD} R_{\mathrm{a}} \quad$ Average percentage difference in average surface roughness

$\mathrm{PD} R_{\max }$ Average percentage difference in maximum surface roughness

$\mathrm{PD} R_{\mathrm{z}} \quad$ Average percentage difference in depth of surface roughness

$\mathrm{PD} f_{\mathrm{p}} \quad$ Average percentage difference in single pitch error

$\mathrm{PD} f_{\mathrm{u}} \quad$ Average percentage difference in adjacent pitch error

$\mathrm{PDF} F_{\mathrm{p}} \quad$ Average percentage difference in cumulative pitch error

$\mathrm{PD} F_{\mathrm{r}} \quad$ Percentage difference in runout

\section{References}

1. G. Goch, Gear metrology, CIRP Ann. - Manuf. Technol. 52 (2003) 659-695

2. B. Karpuschewski, H.J. Knoche, M. Hipke, Gear finishing by abrasive processes, CIRP Ann. - Manuf. Technol. 57 (2008) 621-640

3. S. Pathak, N.K. Jain, I.A. Palani, On surface quality and wear resistance of straight bevel gears finished by pulsed electrochemical honing process, Int. J. Electrochem. Sci. 10 (2015) 8869-8885

4. G. Capello, S. Bertoglio, A new approach by electrochemical finishing of hardened cylindrical gear tooth face, Ann. CIRP 28 (1) (1979) 103-107

5. C. Chen, J. Liu, G. Wei, Electrochemical honing of gears: a new method of gear finishing, Ann. CIRP 30 (1) (1981) 103-106

6. G. Wei, Z. Wang, C. Chen, Field controlled electrochemical honing of gears, Precis. Eng. 9 (4) (1987) 218-221

7. F. He, W. Zhang, K. Nezu, A precision machining of gears: slow scanning field controlled electrochemical honing, Jpn. Soc. Mech. Eng. Int. J. Services 43 (2) (2000) 486-491

8. J. Yi, T. Yang, J. Zhou, New electrochemical process gear tooth-profile modification, Manuf. Technol. Mod. Machine 9 (1) (2000) 102-105

9. J.P. Misra, N.K. Jain, P.K. Jain, Investigations on precision finishing of helical gears by electrochemical honing process, Proc. IMechE, Part B: J. Eng. Manuf. 224 (12) (2010) 1817-1830

10. J.H. Shaikh, N.K. Jain, S. Pathak. Investigations on surface quality improvement of straight bevel gears by electrochemical honing process, Proc. IMechE, Part B: J. Eng. Manuf. 230 (7) (2016) 1242-1253

11. S. Pathak, N.K. Jain, I.A. Palani, Effect of applied voltage and electrolyte parameters on pitch, runout, topography and finishing productivity of the straight bevel gears in PECH process, Mater. Manuf. Process. 32 (2017) 339-347

12. S. Pathak, N.K. Jain, I.A. Palani, Investigations on surface quality, surface integrity and specific energy consumption in finishing of straight bevel gears by PECH process, Int. J. Adv. Manuf. Technol. 85 (2016) 2207-2222

13. S. Pathak, N.K. Jain, I.A. Palani, On use of pulsed electrochemical honing to improve micro-geometry of bevel gears, Mater. Manuf. Process. 29 (2014) 1461-1469

14. S. Pathak, N.K. Jain, I.A. Palani, Effect of honing gear hardness on microgeometry and surface quality improvement of straight bevel gears in PECH process, Int. J. Adv. Manuf. Technol. 85(9) (2016) 2197-2205 